\title{
Asthma in the pediatric population: Level of perception among the parents and guardians
}

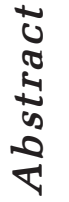

\section{Abdullah Al-Anazi', Mohamed Al Moamary', Taha Ismaeli ${ }^{3}$, Abdullah Nawash Alanazi ${ }^{4}$, LafiHamdan Olayan ${ }^{5}$, Abdullah Mayof Alanazi ${ }^{6}$, Hassan Yassen Abo Noarh ${ }^{7}$, Shoeb Qureshi ${ }^{8}$ \\ ${ }^{1,3-7}$ Respiratory Therapy Program, ${ }^{8}$ Research Coordinator, College of Applied Medical Sciences, ${ }^{2}$ Department of Medicine, College of Medicine, King Saud Bin Abdul-Aziz University for Health Sciences, Riyadh, Saudi Arabia}

Address for the Correspondence:

Dr. Shoeb Qureshi, College of Applied Medical Sciences, King Saud Bin Abdulaziz University, National Guards, Riyadh, Saudi Arabia.

E-mail: qsab2002@yahoo.co.in

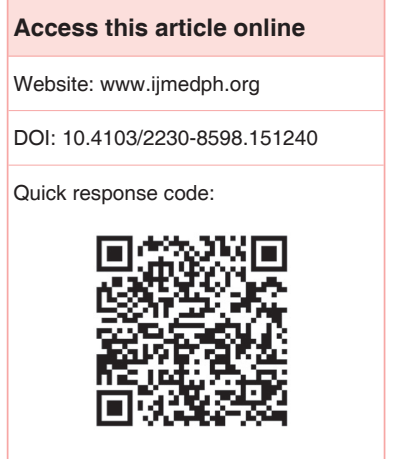

Background: Asthma in the child population is one of the leading public health problems that accounts for immense hospitalization, morbidity, and mortality throughout the world with no exception of the Middle East, including Saudi Arabia. Reports in the literature emphasize on family management of this dreadful disease among the children. Aim: The aim of this study was to investigate the knowledge and perceptions of parents/guardians about childhood asthma. Materials and Methods: Likert scale questionnaire consisting of 90 questions was served to the parents/ guardians of asthmatic children. The questionnaire scores were correlated with the number of emergency department (ED) visits by asthmatic children $(r=-0.239$, $P=0.046$ ). Results: Our results showed a negative correlation between ED visits by asthmatic children and their parents/guardians' knowledge of the disease. Conclusion: Although there is a trend between the ED visits by asthmatic children and the level of parents/guardians' awareness, our results are not conclusive, hence; further studies with a larger sample size are recommended.

Key words: Asthmatic children, emergency department visits, parents/guardians, perception

\section{INTRODUCTION}

There has been a considerable increase in the global Incidence of asthma during the last few decades, the Arab world including Saudi Arabia is no exception. ${ }^{[1,2]}$ Besides, enormous spread of infection, the suffering of asthma attack in children is a cause of enhanced risk of major school absenteeism, which results in future derangement of their social, psychological, and educational adjustment. ${ }^{[3]}$ Increased asthma prevalence, morbidity and mortality have intensified public health concern. ${ }^{[4]}$ Literature reports suggest that the severity of the asthma among children can be greatly controlled by management of the disease by family. ${ }^{[5-7]}$ In a recent study, Zhao, ${ }^{[4]}$ in a recent study found poor control of asthma in children is due to ignorance of the parents/guardians about the disease. Some of these lapses include exposure of the children to adverse environment, the lack of compliance with medications and visits to control asthma, which deteriorates the condition. The health care system in Saudi Arabia has established guidelines for the management and prevention of bronchial asthma, however; little is known about the views and delusions that the parents/guardians of asthmatic patients have about the disease. ${ }^{[8-10]}$ A study conducted on the knowledge of mothers of asthmatic children in Aseer (Saudi Arabia) revealed that they had no knowledge of the complications of breathing exercises during asthma attacks. ${ }^{[1]}$ The present study on the educational component of managing bronchial asthma stems from the relevance of awareness of the disease by the parents/guardians that can be an inhibitory factor in emergency department (ED) visits by asthmatic children. This study is a detailed investigation of our preliminary observation. ${ }^{[12]}$ The concept is more significant to Saudi society because of the variability in ethnic and demographic backgrounds.

\section{MATERIALS AND METHODS}

In order to assess, the level of awareness of parents/guardians of pediatric asthmatic patients, we distributed asthma awareness questionnaire consisting of 90 Likert scale questions to parents/guardians accompanying the asthmatic children to the ED of King Saud Bin Abdulaziz University. Keeping in view the ED admissions, a convenient sample size was 90 subjects. This size was selected as 90 subjects 
was the maximum of patients after considering the exclusion criteria from the total number admitted to the ED. The database system in the hospital enabled us to investigate the admission of the number of the participants.

\section{Inclusion criteria}

The parents/guardians of pediatric asthmatic patients, male or female, more than 1-year-old, who were admitted to the ED due to any asthma symptoms as a chief complaint, were included in the study.

\section{Exclusion criteria}

The parents/guardians of nonasthmatics pediatric patients and pediatric asthmatics less than 1-year-old were excluded from the study.

The pediatric asthmatic patients less than 1-year-old were included in the study of demographic data analysis only and not for correlation analysis. The admission frequency reported in our analysis was taken from the first ED admission due to asthma symptoms, as reported in database system, until the end of the year 2011. To find any correlation between the ED admissions and the level of knowledge about asthma, we categorized our sample into two categories; aware and not aware. Any study subject scored equal to or less than 51 (based on the $25^{\text {th }}$ quartile of the scores) was considered to be not aware, and with scored more than 51 was considered to be aware. Data were incorporated into SPSS (Statistical Package for the Social Sciences) version 20.0.1 and descriptive analysis was performed. We calculated Pearson correlation between the admission frequency and the awareness as a measure of being "aware" or "not aware." Since, the study constituted the companions associating the patients, there was no requirement of the approval of ethical consideration by the International Review Board of the King Abdullah International Medical Research Center, (National Guards). However, patients' confidentiality was strictly observed throughout the study by using the patients' anonymous unique serial number for each subject.

\section{RESULTS}

Our sample included 90 parents/guardians, accompanying the asthmatic children to the ED of King Saud Bin Abdulaziz University. Out of the size of the sample, $95.3 \%$ were Saudis and $4.7 \%$ were Non-Saudis. Twenty-eight percent of the respondents were male and
$72 \%$ females. The percentage of illiteracy among the respondents showed that $27.2 \%$ were high school graduates, and 30.6\% were higher education graduates; $68.4 \%$ of the participants stated that they had enough information about asthma and 31\% stated otherwise. For 70 participants (excluding children less than 1-yearold), we calculated Pearson correlation between parent awareness about asthma and the admission frequency and the analysis showed a negative correlation of $(-0.239, P=0.046)$ between the two variables, which means that the higher the participants score, the less likely are their asthmatic children to have frequent emergency admissions or visits due to asthma. The highest score limit was $85 / 85$, and the lowest was $17 / 85$. However, the maximum score in our study was 71 , and minimum was 34 with a mean score of 53 (standard deviation $=7.1$ ).

\section{DISCUSSION}

Likert scale was followed to frame the questionnaire. The total number of questions were 17 classified into three categories as per recommendations of the original questionnaire article, ${ }^{[13]}$ the categories being the myths and beliefs regarding asthma, level of knowledge about the disease and knowledge about the associated aspects of asthma. Each category was scored separately and then the sum of all categories was calculated.

\section{First category}

First category, myths and beliefs regarding asthma, contained seven questions, each question with a score of 1-5 (total score: 35 ). Scores were fairly average [Table 1]. When questions were analyzed separately, it was found that most of the participants $(62 \%)$ believed that it was the best to go to the ED no sooner the child gets an attack of asthma, irrespective of the magnitude of the symptoms [Figure 1]. This finding strongly correlates with the public panic in the ED even if the disease is manageable at home without a hospital visit. ${ }^{[13-19]}$

\section{Second category}

The second category, level of knowledge about the disease, consisted of 6 questions with a total score of 30 . The results showed the fact that people had knowledge about asthma components even though they lack skills for managing the disease. Most of the findings were linear with a fairly knowledgeable population [Table 2]. In general, this study showed that even among subjects with good knowledge about the disease, the tendency to ED was high. ${ }^{[20-23]}$ This can be

\begin{tabular}{|c|c|c|}
\hline Description & Mean & SD \\
\hline Inhaler use can lead to dependence or addiction & 3.39 & 1.319 \\
\hline Inhalers can have an effect on the heart or damage it & 3.35 & 1.232 \\
\hline It is not good for children to use the inhaler for too long & 2.69 & 1.315 \\
\hline After a child's asthma attack, once the coughing is over, use of the inhaler and medications should stop & 3.12 & 1.387 \\
\hline Children with asthma should use asthma medications only when they have symptoms (coughing, congestion, or wheezing) & 2.65 & 1.305 \\
\hline It is better to use inhalers directly, without a holding chamber, so the medication can go more directly to the lungs & 3.63 & 1.361 \\
\hline When a child has an asthma attack it's best to go to the emergency room even if symptoms are mild & 2.45 & 1.323 \\
\hline
\end{tabular}


explained on the basis of the presence of other factors such as weather, genetic elements, family history and some other social/ pathological triggers. ${ }^{[12,13]}$

\section{Third category}

This category is about knowledge of the associated aspects of asthma. It contained 4 questions with a total score of 20. The results showed that the parents tend to limit child's social and physical activities because of asthma [Tables 3 and 4] even if it could be easily managed with a course of Bronchodilators. ${ }^{[2]}$

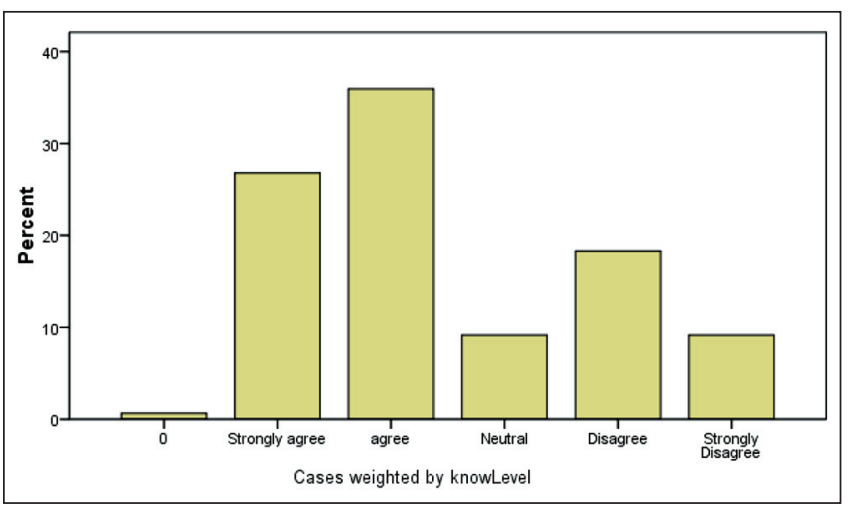

Figure 1: Trend of the parents/guardians of asthmatic children to visit emergency department at the time of asthma attack

\section{Sum of all categories}

The sum of all categories showed a total score of 85 in the questionnaire. Our result indicated that most of the participants were aware of asthma that was an unexpected observation. The reason for this observation is probably a small sample size in this study. This also indicates that our result is not conclusive in nature, but only provides a significant insight into the trends of our study population [Figure 2].

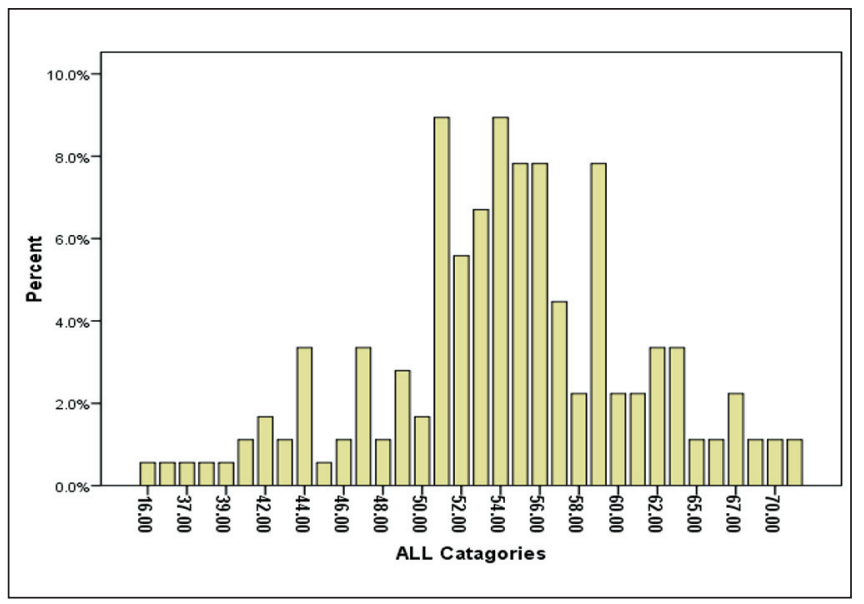

Figure 2: Distribution of questionnaire scores

\section{Table 2: Mean scores of the second category}

\begin{tabular}{|c|c|c|c|}
\hline Description & $n$ (valid) & Mean & SD \\
\hline The main cause of asthma is airway inflammation & 90 & 3.63 & 1.075 \\
\hline Asthma attacks can be prevented if medications are taken even when there are no symptoms-between attacks & 90 & 3.59 & 1.160 \\
\hline Flu infections are the main causes or triggers of asthma attacks & 88 & 3.38 & 1.359 \\
\hline If an asthmatic child gets the flu, you should apply the inhalers even if there's no coughing or wheezing & 90 & 2.99 & 1.259 \\
\hline $\begin{array}{l}\text { Asthmatic children might have attacks that are severe enough to require hospitalization in an intensive care unit or } \\
\text { they might even die from an attack }\end{array}$ & 90 & 4.02 & 1.112 \\
\hline Some medications for asthma do not work unless they are administered every day & 90 & 3.56 & 1.133 \\
\hline
\end{tabular}

\begin{tabular}{lc} 
Table 3: Trends of the parents/guardians of asthmatic children to limit patient's social life (third category \\
questionnaire) & $\begin{array}{c}\text { Percentage } \\
\text { of agreed }\end{array}$ \\
$\begin{array}{l}\text { Percentage } \\
\text { of disagreed }\end{array}$ & 78 \\
\hline $\begin{array}{l}\text { Parents/guardians should ask a doctor to tell the school that an asthmatic child should not exercise or participate } \\
\text { in physical education classes }\end{array}$ & 11 \\
Children who have asthma should not participate in sports that make them run too much & 62 \\
It is best not to smoke or let anyone else smoke near a child who has asthma & 96 \\
If the parents/guardians of a child with asthma smoke outside the house, it won't affect the child & 34 \\
\hline
\end{tabular}

\begin{tabular}{|c|c|c|c|c|c|c|}
\hline Description & $n$ & Minimum & Maximum & Sum & Mean & SD \\
\hline $\begin{array}{l}\text { Parents/guardians should ask a doctor to tell the school that an asthmatic child should not } \\
\text { exercise or participate in physical education classes }\end{array}$ & 179 & 1 & 5 & 363 & 2.03 & 1.062 \\
\hline Children who have asthma should not participate in sports that make them run too much & 177 & 0 & 5 & 455 & 2.57 & 1.176 \\
\hline It is best not to smoke or let anyone else smoke near a child who has asthma & 179 & 1 & 5 & 826 & 4.61 & 0.655 \\
\hline If the parents/guardians of a child with asthma smoke outside the house, it won't affect the child & 179 & 1 & 5 & 476 & 2.66 & 1.465 \\
\hline Valid $n$ (list wise) & 177 & & & & & \\
\hline
\end{tabular}

\footnotetext{
$\mathrm{SD}=$ Standard deviation
} 


\begin{tabular}{lcc} 
Table 5: Correlation between ED visits \\
and questionnaire score \\
\hline Statistical analysis & \multicolumn{2}{c}{ Correlations } \\
\cline { 2 - 3 } & Previous ED visits & All categories \\
\hline Previous ED visits & 1 & \\
Pearson correlation & 1 & -0.239 \\
Significant (2-tailed) & & 0.046 \\
$n$ & & 70 \\
\hline
\end{tabular}

$\mathrm{ED}=$ Emergency department

\section{Correlation of the association between parents/ guardians awareness and ED visits}

Calculating the 25 percentiles $\left(25^{\text {th }} \mathrm{Q}\right)$ yielded a score of 51 , which showed a strong negative correlation between the sum of scores of all categories and patients frequent admissions to $\operatorname{ED}(r=-0.239$, $P=0.046)$. This frequent admission trend can also be explained on the basis of the low score of the participants [Table 5 and Figure 3].

\section{CONCLUSION}

Asthma is one of the most commonly diagnosed diseases in pediatric ED. Most of the asthmatic children brought to the ED are due to recurrent and uncontrolled asthma symptoms. The health care providers like RT, RN and physicians have a good opportunity to educate the parents/guardians of the asthmatic children and increase their level of awareness about the proper control and management of asthma exacerbation that prevents further complications and unnecessary ED admissions. In general, the scores of individual categories were fairly acceptable. Furthermore, negative association was found between the ED visits and the total score of the categories. Nevertheless, the inconclusive results obtained in this study might be related to the small sample size. We recommend further studies to be conducted on a larger sample size to prove significant correlation between the level of knowledge of parents/ guardians of asthmatic children and ED visits.

\section{RECOMMENDATION}

Based on our findings, we recommend implementation of an educational program in our pulmonary rehabilitation center for better management of the disease and to lower the chance of frequent ED visits and frequent admissions. Furthermore, well-aware parents/guardians and lower ED visits/admissions would imply good Asthma control and better life quality.

\section{ACKNOWLEDGMENT}

The authors are thankful to Dr. MotasimBadri, King Fahad Hospital Emergency Department and King Abdullah Medical Research Center for the succor in conduct of this investigation.

\section{REFERENCES}

1. Al Frayh AR, Shakoor Z, Gad EI Rab MO, Hasnain SM. Increased prevalence of asthma in Saudi Arabia. Ann Allergy Asthma Immunol 2001;86:292-6.

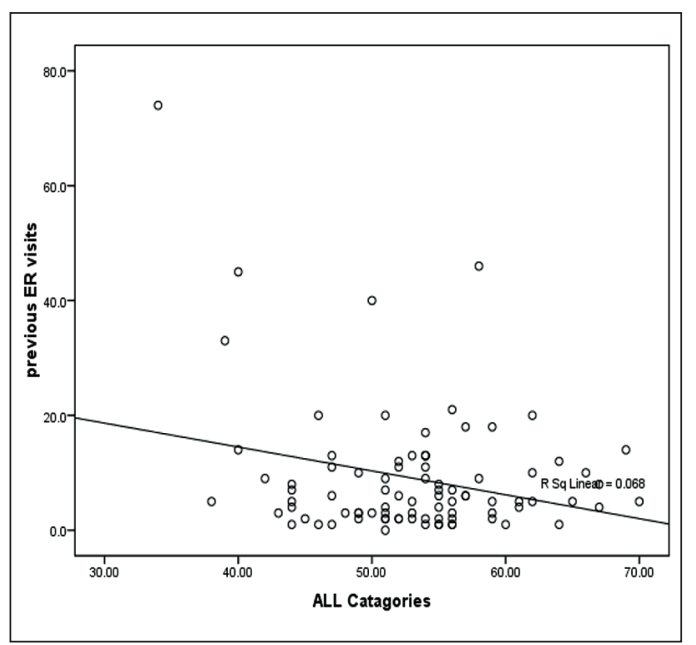

Figure 3: Correlation between previous emergency department visits and questionnaire score

2. Asher Ml. Recent perspectives on global epidemiology of asthma in childhood. Allergol Immunopathol (Madr) 2010;38:83-7.

3. Al-Dawood KM. School boys with bronchial asthma in Al-khobar city, saudi arabia: Are they at increased risk of school absenteeism? J Family Community Med 2001;8:25-33.

4. Zhao J, National Parents of Asthmatic Children KAP Project Team. Asthma control status in children and related factors in 29 cities of China. Zhonghua Er Ke Za Zhi 2013;51:90-5.

5. Deatrick JA, Knafl KA. Management behaviors: Day-to-day adjustments to childhood chronic conditions. J Pediatr Nurs 1990;5:15-22.

6. Ray LD, Ritchie JA. Caring for chronically ill children at home: Factors that influence parents' coping. J Pediatr Nurs 1993;8:217-25.

7. Donnelly E. Parents of children with asthma: An examination of family hardiness, family stressors, and family functioning. J Pediatr Nurs 1994;9:398-408.

8. Plaut TF, Hershey JE, Bendich DM, Katz HP, Schoen EJ. Is asthma misdiagnosed? J Asthma 1986;23:23-4.

9. Dinakar C, Van Osdol TJ, Wible K. How frequent are asthma exacerbations in a pediatric primary care setting and do written asthma action plans help in their management? J Asthma 2004;41:807-12.

10. Dozier A, Aligne CA, Schlabach MB. What is asthma control? Discrepancies between parents' perceptions and official definitions. J Sch Health 2006;76:215-8.

11. Al-Binali AM, Mahfouz AA, Al-Fifi S, Naser SM, Al-Gelban KS. Asthma knowledge and behaviours among mothers of asthmatic children in Aseer, south-west Saudi Arabia. East Mediterr Health J 2010;16:1153-8.

12. Al-Anazi A, Al Moamary M, Ismaeil T, Alanazi AN, Olayan LH, Alanazi AM, et al. Frequent emergency department visits and parents/guardians' level of awareness of asthma in the pediatric population. J Emerg Trauma Shock 2014;7:133-4.

13. Rodríguez Martínez C, Sossa MP. Validation of an asthma knowledge questionnaire for use in parents or guardians of children with asthma. Arch Bronconeumol 2005;41:419-24.

14. Haire-Joshu D, Fisher EB Jr, Munro J, Wedner HJ. A comparison of patient attitudes toward asthma self-management among acute and preventive care settings. J Asthma 1993;30:359-71.

15. Schulz RM, Dye J, Jolicoeur L, Cafferty T, Watson J. Quality-of-life factors for parents of children with asthma. J Asthma 1994;31:209-19.

16. Lal A, Kumar L, Malhotra S. Knowledge of asthma among parents of asthmatic children. Indian Pediatr 1995;32:649-55.

17. Wong E, Wong TW, Chung M, Lau CC. Knowledge and beliefs of parents of asthmatic children presenting to an emergency. Hong Kong J Emerg Med 2001;8:202-6.

18. Borrelli B, McQuaid EL, Becker B, Hammond K, Papandonatos G, Fritz G, et al. Motivating parents of kids with asthma to quit smoking: The PAQS project. Health Educ Res 2002;17:659-69. 
19. Chiang LC, Huang JL, Yeh KW, Lu CM. Effects of a self-management asthma educational program in Taiwan based on precede-proceed model for parents with asthmatic children. J Asthma 2004;41:205-15.

20. Stanford R, McLaughlin T, Okamoto LJ. The cost of asthma in the emergency department and hospital. Am J Respir Crit Care Med 1999;160:211-5.

21. Gibson PG, Henry RL, Vimpani GV, Halliday J. Asthma knowledge, attitudes, and quality of life in adolescents. Arch Dis Child 1995;73:321-6.

22. Van Asperen P, Jandera E, De Neef J, Hill P, Law N. Education in childhood asthma: A preliminary study of need and efficacy. Aust Paediatr J 1986;22:49-52.
23. Lenfant C, Hurd SS. National Asthma Education Program. Chest 1990;98:226-7.

24. Eggleston PA, Malveaux FJ, Butz AM, Huss K, Thompson L, Kolodner K, et al. Medications used by children with asthma living in the inner city. Pediatrics 1998;101:349-54

How to cite this article: Al-Anazi A, Al Moamary M, Ismaeli T, Alanazi AN, Olayan L, Alanazi AM, et al. Asthma in the pediatric population: Level of perception among the parents and guardians. Int J Med Public Health 2015;5:14-8.

Source of Support: Nil, Conflict of Interest: None declared. 